\title{
TNF-alpha and melphalan-based isolated limb perfusion: no evidence supporting the early destruction of tumour vasculature
}

\author{
L E Podleska*, ${ }^{*}$, K Funk ${ }^{2}$, L Umutlu ${ }^{3}$, F Grabellus ${ }^{4}$, G Taeger ${ }^{1}$ and H de Groot ${ }^{2}$ \\ ${ }^{1}$ Section for Sarcoma Surgery, Department of General, Visceral and Transplantation Surgery, University Hospital of Essen and \\ Sarcoma Center at the West German Cancer Center (WTZ), University of Duisburg-Essen, Hufelandstrasse 55, D-45122 Essen, \\ Germany; ${ }^{2}$ Institut für Physiologische Chemie, Universitätsklinikum Essen, Hufelandstrasse 55, D-45122 Essen, Germany; \\ ${ }^{3}$ Department of Diagnostic and Interventional Radiology and Neuroradiology, University Hospital of Essen and Sarcoma Center \\ at the West German Cancer Center (WTZ), University of Duisburg-Essen, Hufelandstrasse 55, D-45122 Essen, Germany and \\ ${ }^{4}$ Zentrum fuer Pathologie Essen-Mitte, ZPEM, Am Deimelsberg 34a, D-45276 Essen, Germany
}

Background: Isolated limb perfusion with TNF-alpha and melphalan (TM-ILP) is a highly effective treatment for locally advanced tumours of the extremities. Previous research suggests an almost immediate disintegration of the blood supply of the tumour. The aim of the present study was to verify this hypothesis using non-invasive measurements of microvascular perfusion and tissue oxygenation.

Methods: A total of 11 patients were included in the study. TM-ILP was performed under mildly hyperthermic conditions $\left(39^{\circ} \mathrm{C}\right)$ in the extremities via proximal vascular access. Capillary-venous microvascular blood flow, haemoglobin level $(\mathrm{Hb})$ and oxygen saturation $\left(\mathrm{SO}_{2}\right)$ were determined using laser Doppler and white-light spectroscopy, respectively, before TM-ILP and at $30 \mathrm{~min}, 4 \mathrm{~h}$, 1 day, 4 days, 1 week, 2 weeks and 6 weeks after TM-ILP from tumour and healthy muscle tissues.

Results: Blood flow and $\mathrm{Hb}$ were mostly higher, whereas $\mathrm{SO}_{2}$ was lower, in tumour tissue compared with muscle tissue. In both tumour and muscle tissues, blood flow significantly increased immediately after TM-ILP and remained elevated for at least 2 weeks, followed by a return to the initial values 6 weeks after the procedure.

Conclusion: No signs were found of early destruction of the tumour vasculature. The observations suggest that an inflammatory reaction is one of the key elements of TM-ILP.

Isolated limb perfusion with TNF-alpha and melphalan (TM-ILP) is one of the most effective treatment options for locally advanced soft tissue sarcoma (STS) and malignant melanoma of the limbs. For STS, TM-ILP enables limb salvage rates that exceed $80 \%$; response rates for malignant melanoma are even higher, with a combined complete and partial remission rate of $\sim 90 \%$ (Grunhagen et al, 2006; Taeger et al, 2008; Deroose et al, 2011a, 2012). Tumour vascularisation and oxygenation are known to have key roles in tumour growth and progression (Rofstad and Danielsen, 1998; Hendriksen et al, 2009). TM-ILP is thought to primarily target the tumour vasculature (de Wilt et al, 2000;
Hoving et al, 2006). Recently, a minimally invasive study reported a significant decrease in tumour oxygenation during TM-ILP (Jakob et al, 2012). However, there is currently little information regarding tumour oxygenation and, in particular, microvascular blood flow in the tumour during and following clinical application of TM-ILP. This lack of information might be attributed to the fact that most oxygen measurements in tumour tissue require invasive procedures (Vaupel et al, 1991; Nordsmark et al, 2001).

Recently, a new technique to non-invasively measure microvascular blood flow and tissue oxygenation using laser Doppler and white-light spectroscopy has been introduced (Beckert et al, 2004; 
Jorgensen and Schroeder, 2012). Here, we applied this technique to examine changes in blood flow, tissue oxygen saturation $\left(\mathrm{SO}_{2}\right)$ and haemoglobin level $(\mathrm{Hb})$ in a clinical setting from before TM-ILP to 6 weeks after TM-ILP.

\section{MATERIALS AND METHODS}

Patients. All patients included in this study were treated with TMILP at the West German Cancer Centre at the University Hospital of Essen, a tertiary referral centre for STS and melanoma. The patients were informed of the experimental nature of this investigation and provided informed consent. The study was conducted between March and September 2011. Owing to the maximum depth limitation of $2 \mathrm{~cm}$ for the probes, only patients whose tumours were located less than $2 \mathrm{~cm}$ below the skin level according to the pre-operative MRI scan were selected.

TM-ILP. Isolated limb perfusion was performed as previously described (Grabellus et al, 2011, 2012a). Vascular access was established via a femoral or an iliac approach for the lower limb or via a brachial or an axillary approach for the upper limb. A tourniquet (either an Esmarch bandage for axillary or iliac perfusion or a pneumatic tourniquet for brachial or femoral perfusion) was applied to isolate systemic circulation from the limb circulation. After extracorporeal circulation was established using a heart-lung machine (Stöckert S3, Sorin Group, Milan, Italy), the limb was heated to establish mild hyperthermia (between 38.5 and $39^{\circ} \mathrm{C}$ for the upper limb and between 39 and $39.5^{\circ} \mathrm{C}$ for the lower limb). All patients received continuous leakage monitoring using indium-labelled albumin and precordial gamma-probe detection. TNF-alpha (Beromun, Boehringer-Ingelheim, Ingelheim, Germany) was applied at a dosage of $1 \mathrm{mg}$ for the upper limbs and $2 \mathrm{mg}$ for the lower limbs. After $15 \mathrm{~min}$, melphalan (L-phenylalanine mustard) was added into circulation $\left(11 \mathrm{mgl}^{-1}\right.$ of limb volume for the legs and $13 \mathrm{mgl}^{-1}$ for the arms), and perfusion was continued for another $60 \mathrm{~min}$. The limb was then rinsed with 3-61 of hydroxyethylstarch (HAES 10\%, Fresenius Kabi, Bad Homburg, Germany), the catheters and tourniquet were removed and the vessels and wounds were closed with sutures.

MRI. MRI scans served as the baseline examination and were performed 1 day before TM-ILP. To evaluate tumour regression, the same examination was performed 6 weeks after TM-ILP, according to the informal consensus of the centres that perform TM-ILP for advanced limb sarcoma. MRI scans included native T1 and $\mathrm{T} 2$ in transversal planes and a short tau inversion recovery sequence. Contrast-medium-enhanced sequences included a transversal sequence and a coronal T1 sequence with fat suppression. Measurement of the tumour diameter and contrast medium uptake was performed by the same radiologist (LU), who was blinded to the histopathology and $\mathrm{O} 2 \mathrm{C}$ results. The tumour diameters (in $\mathrm{mm}$ ) before (pre-TMP-ILP) and after (post TM-ILP) were measured in all three planes at the maximum diameter. The corresponding values were multiplied $(x \cdot y \cdot z)$, and then the fractional changes in the tumour volumes were computed (post-ILP volumes divided by pre-ILP volumes). The resulting quotient (in per cent) equals the tumour volume after TM-ILP relative to the initial tumour volume (before ILP). Contrast medium enhancement was comparatively (pre- to post-ILP) estimated on a 4 -grade scale (which ranged from 0 out of 4 for no contrast medium enhancement to 4 out of 4 for full contrast medium enhancement) and translated to a percentage scale.

Histopathology. If resection of the tumour was part of the multidisciplinary treatment protocol, resection of the residual tumour was performed shortly after the second MRI scan (7-9 weeks after TM-ILP). All specimens were fixated in $4 \%$ neutral-buffered formalin. A gross estimation of tumour necrosis was recorded, and a minimum of one block per centimetre of the largest diameter of the tumour was collected. Basic microscopic evaluation was performed from haematoxylin and eosin-stained slides. The tumours were typed according to the 'WHO classification of tumours of soft tissue and bone' (Fletcher et al, 2013). Grading was performed using primary biopsies according to the French Fédération Nationale des Centres de Lutte Contre le Cancer. The overall regression was assessed using light microscopy and was determined as a percentage of the devitalised tumour after TM-ILP. The tumour regression was graded using the six-stage grading scale of Salzer-Kuntschik (Salzer-Kuntschik et al, 1983).

Microvascular $\mathrm{Hb}, \mathrm{SO}_{2}$ and blood flow. Microvascular $\mathrm{Hb}, \mathrm{SO}_{2}$ and blood flow were measured using a combination of white light spectroscopy and laser Doppler flowmetry (O2C, Oxygen2see, LEA Medizintechnik, Giessen, Germany). White light and laser light are transmitted to the tissue and scattered back to the probe. The scattered white light measures the capillary-venous $\mathrm{SO}_{2}$ and $\mathrm{Hb}$ of the tissue, thereby indicating blood filling of the microvessels. Laser Doppler spectroscopy enables the measurement of moving erythrocytes, which is a marker of microvascular blood flow in the respective tissue volume.

Microvascular blood flow and $\mathrm{Hb}$ are presented as arbitrary units (AU), with blood flow ranging from 0 to $4000 \mathrm{AU}$ (resolution $\pm 1 \mathrm{AU}$ ) and $\mathrm{Hb}$ ranging from 0 to $120 \mathrm{AU}$ (resolution $\pm 1 \mathrm{AU}$ ). The $\mathrm{SO}_{2}$ values are presented in relative units (0-100\%). Both AU values and the $\mathrm{SO}_{2}$ value are calculated from the electrical reading in the $\mathrm{O} 2 \mathrm{C}$ unit. The manufacturer provides normal and critical ranges for orientation purposes (Table 1). In contrast to pulse oximetry, which detects the arterial oxygenation, the $\mathrm{SO}_{2}$ data provided by the $\mathrm{O} 2 \mathrm{C}$ reflect $\mathrm{SO}_{2}$ in the venous portion of the capillary vessels, indicating the oxygen not consumed by cells. Because hypoxia will manifest first in the capillary-venous portion of the vessels, the $\mathrm{O} 2 \mathrm{C}$ measurement is markedly sensitive to hypoxia. The venous $\mathrm{SO}_{2}$ is supplied as a percentage value $(0-100 \%)$, although these values and their interpretation differ significantly from the established values of arterial $\mathrm{SO}_{2}$. As shown in Table 1, normal values range from $20-50 \%$, and critical hypoxia is encountered when values drop below $10 \%$.

Tumour depth measurements, measuring depth and probe placement. According to the manufacturer's instructions, with $\mathrm{O} 2 \mathrm{C}$, a measuring depth of up to $2 \mathrm{~cm}$ is possible, depending on the optical parameters of the tissue (Derfuss, 2012). The volume measured by $\mathrm{O} 2 \mathrm{C}$ can be approximated as a cylinder or a cone under the probe. For non-invasive measurement of the microcirculation, we used a glass fibre probe that covered an area of 12 by $44.5 \mathrm{~mm}$ and reached a measurement depth of as much as $20 \mathrm{~mm}$. Because of the lack of available information regarding the signal and measurement quality relative to the distance between the probe and the tissue to be measured, we adapted the method of Beckert et al (2004) and stratified the tumour depths into superficial $(0-5 \mathrm{~mm})$ and deep $(6-20 \mathrm{~mm})$ tumours. The tumour depths were derived from the pre-operative MRI scans. The values were defined according to the minimum distance of the tumour from the surface of the skin. For each patient, two probes were

\begin{tabular}{|c|c|c|}
\hline & Normal values & Critical values \\
\hline $\mathrm{Hb}$ & $35-90 \mathrm{AU}$ & $<15 \mathrm{AU}$ or $>90 \mathrm{AU}$ \\
\hline $\mathrm{SO}_{2}$ & $20-50 \%$ & $<10 \%$ \\
\hline Flow & $10-50 \mathrm{AU}$ & $<5 \mathrm{AU}$ \\
\hline
\end{tabular}


used. The first one was placed at the point at which the tumour was closest to the surface of the skin (this was usually also in the middle of the tumour at the largest diameter). The second one was placed above the most superficial, ipsilateral, healthy muscle for control measurements (the tibialis anterior, usually at mid-shaft height, for leg tumours and the brachioradialis muscle for arm tumours). Markings were drawn around the probe (Edding 3000 permanent marker; Edding International, Ahrensburg, Germany) such that the colour would not interfere with measurements. Both probes (muscle and tumour) were placed according to the markings, fixed in place with adhesive tape (Kimberly-Clark, Roswell, NM, USA) and left there throughout the measurement period. Patients were then asked to keep still for $5 \mathrm{~min}$, and $\mathrm{O} 2 \mathrm{C}$ measurements were collected over a 2-minute period at each probe site. The probes were removed after the measurement and relocated for the following measurements at the previously applied markings.

Readings were taken at predefined time points before and after TM-ILP, as shown in Table 2. We selected a general period of 6 weeks, with the first measurements taken directly before TM-ILP and the last measurements taken 6 weeks after TM-ILP on the same day as the 6-week-post-ILP MRI, at which point the clinical follow-up was scheduled and the resection of the tumour was planned (if the tumour was resected, the resection was performed after the 6-week-post-ILP MRI scan and thus after the 6-week O2C measurement).

Statistics. Statistics were calculated using IBM SPSS 22 (IBM, Armonk, NY, USA). The means, medians and standard deviations

\section{Table 2. Time points at which the readings were taken.}

\begin{tabular}{|l|l|}
\hline Before ILP & 1 Day before ILP (pre-ILP-MRI scan) \\
\hline $30 \mathrm{~min}$ & $\begin{array}{l}\text { After the end of the ILP procedure (30 min after reperfusion } \\
\text { of the extremity) }\end{array}$ \\
\hline $4 \mathrm{~h}$ & $4 \mathrm{~h}$ after ILP \\
\hline $1 \mathrm{~d}$ & 1 Day after ILP \\
\hline $4 \mathrm{~d}$ & 4 Days after ILP \\
\hline $1 \mathrm{wk}$ & 1 Week after ILP (before discharge from hospital) \\
\hline $2 \mathrm{wks}$ & 2 Weeks after ILP (during clinical follow-up) \\
\hline 6 wks & 6 Weeks after ILP (post-ILP-MRI scan) \\
\hline $\begin{array}{l}\text { Abbreviations: HLM = heart-lung machine; ILP = Isolated limb perfusion; MRI = magnetic } \\
\text { resonance imaging. }\end{array}$ \\
\hline
\end{tabular}

(s.d.) were calculated for each time period. Two-tailed significance was calculated using the two-sample $t$-test. A $P$-value below 0.05 was considered significant. Diagrams are displayed as bar graphs (the bars indicate the means, and the error bars indicate one s.d.).

\section{RESULTS}

A total of 11 patients with a median age of 60 years (range, 44-82 years) were included in this study. Within this group, nine patients (eight patients with leg tumours and one patient with a forearm tumour) were suffering from STS. One patient was suffering from malignant melanoma and multiple in-transit metastases of the lower leg and thigh, and one patient had high-grade squamous cell carcinoma of the bone and muscle of the lower leg, which represented a solitary primary tumour (STS-like carcinoma).

The median tumour depth was $6 \mathrm{~mm}$ (range, 1-17 mm). There were five patients in the superficial tumour group, with tumour depths ranging from 1 to $3 \mathrm{~mm}$ (median, $2 \mathrm{~mm}$ ), and six patients in the deep tumour group, with tumour depths ranging from 6 to $17 \mathrm{~mm}$ (median, $8.5 \mathrm{~mm}$ ).

Hb. Figure 1 shows $\mathrm{Hb}$ in tumour and muscle tissues. In the deep tumour group (Figure 1A), there were no significant timedependent changes and no significant differences between tumour and muscle tissues. In the superficial tumour group (Figure 1B), the $\mathrm{Hb}$ was significantly higher in tumour tissue compared with muscle tissue before TM-ILP (tumour: $56 \mathrm{AU}$; muscle: $31 \mathrm{AU}$ ) and 30 min after TM-ILP (tumour: $53 \mathrm{AU}$; muscle: $33 \mathrm{AU}$ ). The $\mathrm{Hb}$ level led off to baseline values 6 weeks after TM-ILP (40 AU for both muscle and tumour). Considering the high initial values in the superficial tumour group, there was also a significant decrease in the tumour $\mathrm{Hb}$ from $56 \mathrm{AU}$ before treatment to $40 \mathrm{AU} 6$ weeks after treatment.

$\mathrm{SO}_{2}$. In the deep tumour group (Figure $2 \mathrm{~A}$ ), $\mathrm{SO}_{2}$ remained nearly constant throughout the observation period, with no significant differences between muscle and tumour tissues. In the superficial tumour group (Figure 2B), similar results were observed with one exception: $30 \mathrm{~min}$ after TM-ILP, there was a significantly lower $\mathrm{SO}_{2}$ of $35 \%$ in the tumour tissue compared with the muscle tissue, which remained constant at $75 \%$. This effect, however, had already disappeared by the next measurement ( $4 \mathrm{~h}$ after TM-ILP), and

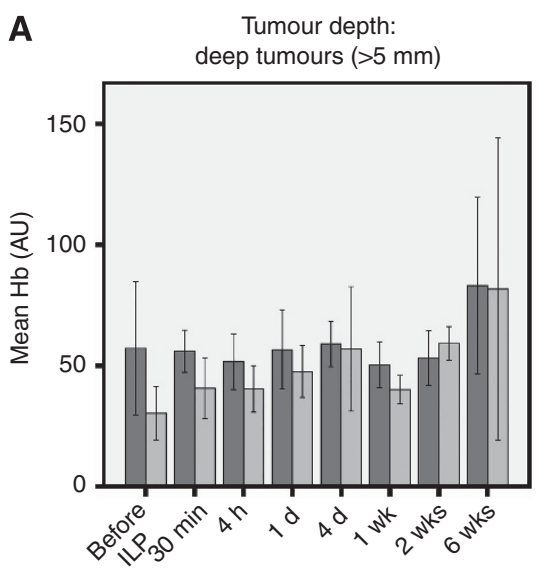

Time after ILP

Error bars: $\pm 1 \mathrm{SD}$

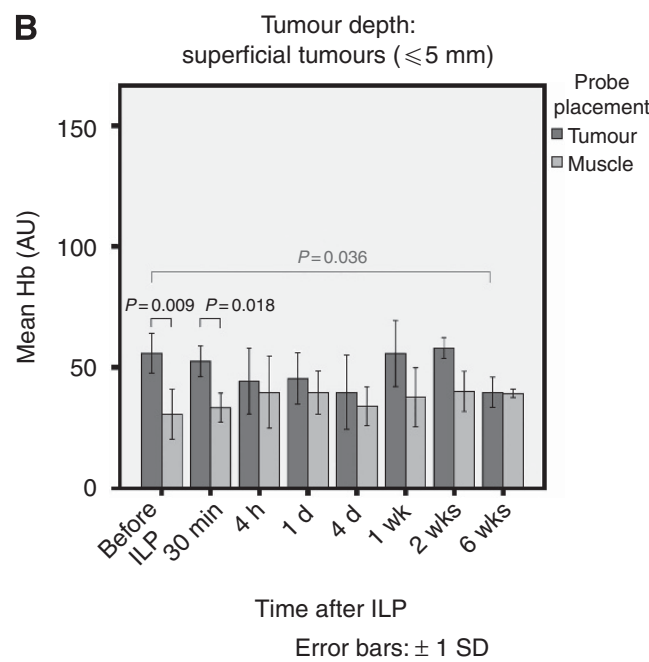

Figure 1. Haemoglobin levels in tumour and muscle tissues for deep (A) and superficial (B) tumours. In the superficial tumour group (Diagram B), there was a significantly higher haemoglobin content in tumour tissue compared with muscle tissue before TM-ILP $(P=0.009)$ and 30 min after TMILP $(P=0.018)$; the values for the two tissue types were similar by 6 weeks after TM-ILP. In terms of time-dependent alterations in the superficial tumour group, a significant decrease was observed in the tumour haemoglobin content from before to 6 weeks after TM-ILP $(P=0.036)$. 
tumour oxygenation returned to normal values, around the $70 \%$ range, within the first $24 \mathrm{~h}$ after TM-ILP.

Blood flow. Both in the deep and superficial tumour groups, as well as in their respective tumour and muscle tissues, microvascular blood flow was similar following TM-ILP (Figure 3). Blood flow significantly increased immediately after TM-ILP and remained elevated until the second to last measuring point ( 2 weeks after TM-ILP), but then returned to the initial values at
6 weeks after TM-ILP. At each time point measured both before and following TM-ILP, blood flow was somewhat higher in tumour tissue than in muscle tissue. The last measurement, 6 weeks after TM-ILP, was the one exception: blood flow in the tumour tissue level led off to the low flow rate observed in muscle tissue.

MRI-based evaluation. As indicated by the MRI scans (Table 3), the mean regression in tumour volume was $64 \%$ (volume of the tumour after TM-ILP compared with the pre-ILP-measurements).
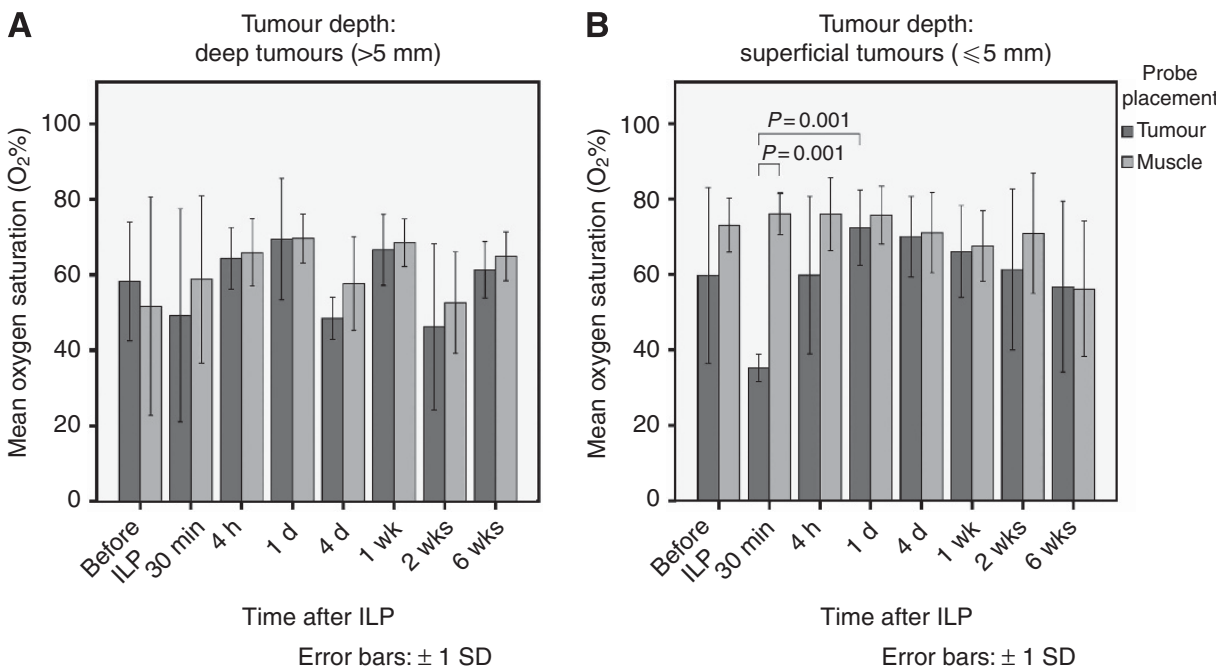

Figure 2. The mean oxygen saturation for $\operatorname{deep}(\mathbf{A})$ and superficial (B) tumours. No significant time-dependent changes or differences in oxygen saturation between muscle and tumour tissues in the deep tumour group (A) were observed. In the superficial tumour group (B), there was a constant oxygen saturation level, with a significant difference between tumour and muscle tissues 30 min after TM-ILP. At this point, the oxygen saturation of the tumour was significantly less than that of the muscle; this difference was highly significant $(P=0.001)$. This effect was already gone by the next measurement ( $4 \mathrm{~h}$ after TM-ILP), and the values returned to the baseline values within the first $24 \mathrm{~h}$ after TM-ILP. In terms of the time-dependent changes, the decrease in tumour oxygenation from before TM-ILP to $30 \mathrm{~min}$ after TM-ILP did exhibit a trend; however, because of the high variance in the values before ILP, this decrease was not significant ( $P=0.139)$. The increase from 30 min after TM-ILP to 1 day after ILP was highly significant $(P=0.001)$

A

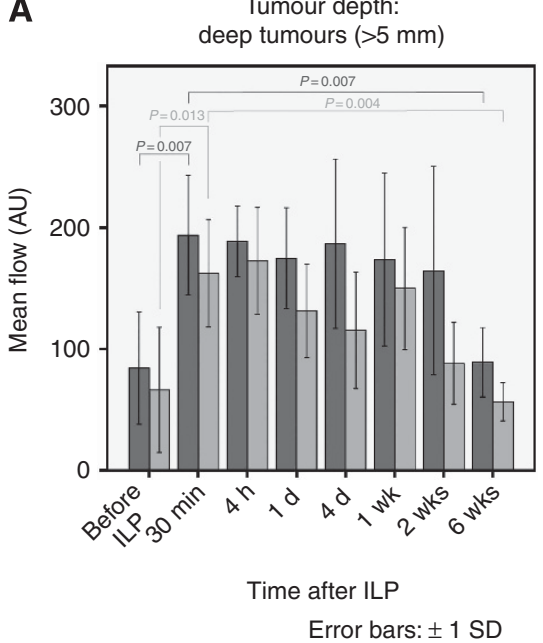

B

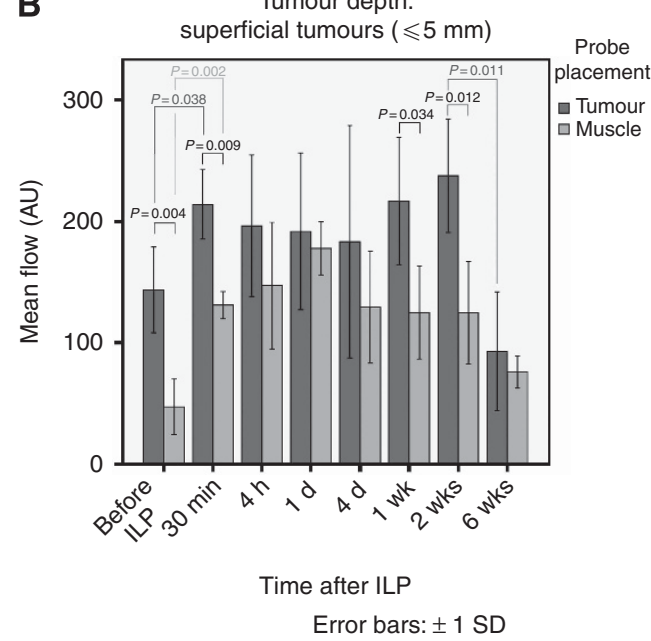

Figure 3. Microvascular blood flow for $\operatorname{deep}(\mathbf{A})$ and superficial $(\mathbf{B})$ tumours. Among the deep tumours (A), there were significant increases in the microvascular blood flow from before to $30 \mathrm{~min}$ after TM-ILP for both tumour tissue $(P=0.007)$ and muscle tissue $(P=0.013)$. Between 30 min and 6 weeks after TM-ILP, there were again significant decreases for tumour tissue $(P=0.007)$ and muscle tissue $(P=0.004)$. Although both flow rates remained elevated, no significant changes were observed because of greater within-group variance. In the superficial tumour group (B), there was a significantly higher flow in tumour tissue than in muscle tissue both before $(P=0.004)$ and 30 min after TM-ILP $(P=0.009)$. This difference in flow remained highly significant at 1 week $(P=0.034)$ and 2 weeks $(P=0.012)$ after TM-ILP, but it was not observed 6 weeks after TM-ILP, at which point the flow rates were similarly low. The superficial tumour group (B) also exhibited time-dependent changes. There was a significant increase in the flow rate from before TM-ILP to $30 \mathrm{~min}$ after TM-ILP for both tumour $(P=0.038)$ and muscle tissues $(P=0.002)$. The flow rate remained elevated for 2 weeks after TM-ILP. Between 2 and 6 weeks after TM-ILP, the flow rate for tumour tissue decreased significantly $(P=0.011)$. 
The minimum tumour volume after ILP was $22 \%$. There were only two patients with a residual tumour volume of less than $50 \%$ of the pre-ILP tumour. Regarding the reduction in the contrast medium uptake, the mean residual uptake was $61 \%$ compared with pre-TMILP scans. Figures 4 and 5 show two cases of STS, before and 6 weeks after TM-ILP. The first case (Figure 4) exhibited a good response in terms of the decrease in size $(22 \%)$ and contrast medium enhancement (50\%). The second case (Figure 5) exhibited the typical behaviour of a moderate decrease in size $(55 \%)$ and a strong reduction in contrast medium enhancement (25\%).

Histopathology. Histopathological examination of resection specimens $(n=5)$ indicated that the mean response was $74 \%$. One out of five cases responded poorly, with only $5 \%$ tumour regression, and all other tumours exhibited regression of greater than $80 \%$. The histopathologically determined regression and the MRI-determined regression did not correspond well. Two out of the five cases exhibited greater than $80 \%$ response according to histopathological examination but no significant decrease in tumour size or MRI contrast medium enhancement.

Clinical observation. Immediately after TM-ILP, local signs of an inflammatory reaction with reddening and swelling developed and persisted for 2 to 6 weeks. These changes homogenously affected the entire extremity included in the perfusion (up to the location of the tourniquet).

\section{DISCUSSION}

Isolated limb perfusion with TM-ILP is able to deliver high local toxicity to tumour tissue, regardless of the tumour type; sarcoma, melanoma and even progressive desmoid tumours are all considered highly responsive to TM-ILP (Eggermont et al, 1996; Bonvalot et al, 2009; Deroose et al, 2011b). To achieve this therapeutic effect, both TNF-alpha and melphalan are required (Posner et al, 1995; Hoving et al, 2006). Inducing an inflammatory

Table 3. Patient data, status and treatment results from MRI scans and from histopathology

\begin{tabular}{|c|c|c|c|c|c|c|c|c|c|c|}
\hline \multirow[b]{2}{*}{ Pat.-No. } & \multirow[b]{2}{*}{ Age } & \multirow[b]{2}{*}{$\begin{array}{l}\text { Clinical } \\
\text { status }\end{array}$} & \multirow[b]{2}{*}{ Resection } & \multicolumn{4}{|c|}{ MRI } & \multicolumn{3}{|c|}{ Histopathology } \\
\hline & & & & $\begin{array}{l}\text { Pre- to post-ILP } \\
\text { contrast medium } \\
\text { enhancement } \\
(\%)\end{array}$ & $\begin{array}{c}\text { Max. tumour } \\
\text { diameter } \\
\text { (mm) before } \\
\text { TM-ILP }\end{array}$ & $\begin{array}{c}\text { Tumour } \\
\text { depth } \\
(\mathrm{mm})\end{array}$ & $\begin{array}{c}\text { Pre- to } \\
\text { post- } \\
\text { ILP MRI } \\
\text { tumour- } \\
\text { volume } \\
(\%)\end{array}$ & $\begin{array}{l}\text { Grade of } \\
\text { regression } \\
\text { (Salzer- } \\
\text { Kuntschik) }\end{array}$ & $\begin{array}{c}\text { Histopatho } \\
\text { logic } \\
\text { regression } \\
(\%)\end{array}$ & Entity \\
\hline 1 & 46 & $\begin{array}{l}\text { No local } \\
\text { recurrence }\end{array}$ & Resection & 25 & 115 & 9 & 55 & 1 & 100 & $\begin{array}{l}\text { Undifferentiated } \\
\text { pleomorphic } \\
\text { sarcoma }\end{array}$ \\
\hline 2 & 61 & $\begin{array}{l}\text { Late } \\
\text { progressive } \\
\text { disease }\end{array}$ & $\begin{array}{c}\text { No } \\
\text { resection }\end{array}$ & 50 & 53 & 17 & 61 & & & Fibrosarcoma \\
\hline 3 & 75 & $\begin{array}{l}\text { No local } \\
\text { recurrence }\end{array}$ & Resection & 100 & 119 & 8 & 60 & 5 & 5 & $\begin{array}{l}\text { Dedifferentiated } \\
\text { liposarcoma }\end{array}$ \\
\hline 4 & 76 & $\begin{array}{l}\text { Systemic } \\
\text { progression } \\
\text { of disease }\end{array}$ & $\begin{array}{c}\text { No } \\
\text { resection }\end{array}$ & 25 & 66 & 2 & 63 & & & Synovial sarcoma \\
\hline 5 & 44 & $\begin{array}{l}\text { No local } \\
\text { recurrence }\end{array}$ & Resection & 90 & 111 & 10 & 93 & 4 & 80 & $\begin{array}{l}\text { Myxoid round cell } \\
\text { liposarcoma }\end{array}$ \\
\hline 6 & 59 & $\begin{array}{l}\text { No local } \\
\text { recurrence }\end{array}$ & Resection & 100 & 42 & 2 & 102 & 3 & 93 & $\begin{array}{l}\text { Undifferentiated } \\
\text { pleomorphic } \\
\text { sarcoma of the } \\
\text { inflammatory type }\end{array}$ \\
\hline 7 & 68 & $\begin{array}{l}\text { Late local } \\
\text { recurrence }\end{array}$ & $\begin{array}{c}\text { No } \\
\text { resection }\end{array}$ & 50 & 19 & 6 & 22 & & & Fibroblastic sarcoma \\
\hline 8 & 82 & $\begin{array}{l}\text { Tumour- } \\
\text { related } \\
\text { death }\end{array}$ & $\begin{array}{c}\text { No } \\
\text { resection }\end{array}$ & 25 & 37 & 1 & 43 & & & $\begin{array}{l}\text { Undifferentiated } \\
\text { pleomorphic } \\
\text { sarcoma (spindle } \\
\text { cell) }\end{array}$ \\
\hline 9 & 44 & $\begin{array}{l}\text { Lost to } \\
\text { follow-up }\end{array}$ & - & Lost to follow-up & - & 7 & & & & $\begin{array}{l}\text { Undifferentiated } \\
\text { pleomorphic } \\
\text { sarcoma }\end{array}$ \\
\hline 10 & 52 & $\begin{array}{l}\text { Local } \\
\text { recurrence }\end{array}$ & Resection & 50 & 68 & 3 & 103 & 3 & 93 & $\begin{array}{l}\text { Squamous cell } \\
\text { carcinoma }\end{array}$ \\
\hline 11 & 80 & $\begin{array}{l}\text { Ongoing } \\
\text { complete } \\
\text { remission }\end{array}$ & $\begin{array}{c}\text { No } \\
\text { resection }\end{array}$ & 90 & 25 & 3 & 36 & & & $\begin{array}{l}\text { Malignant } \\
\text { melanoma }\end{array}$ \\
\hline Mean & & & & 61 & 66 & 6 & 64 & & 74 & \\
\hline Median & & & & 50 & 60 & 6 & 61 & & 93 & \\
\hline Minimum & & & & 25 & 19 & 1 & 22 & & 5 & \\
\hline Maximum & & & & 100 & 119 & 17 & 103 & & 100 & \\
\hline SD & & & & 31.6 & 37.6 & 4.8 & 27.7 & & 39.4 & \\
\hline
\end{tabular}


Before TM-ILP
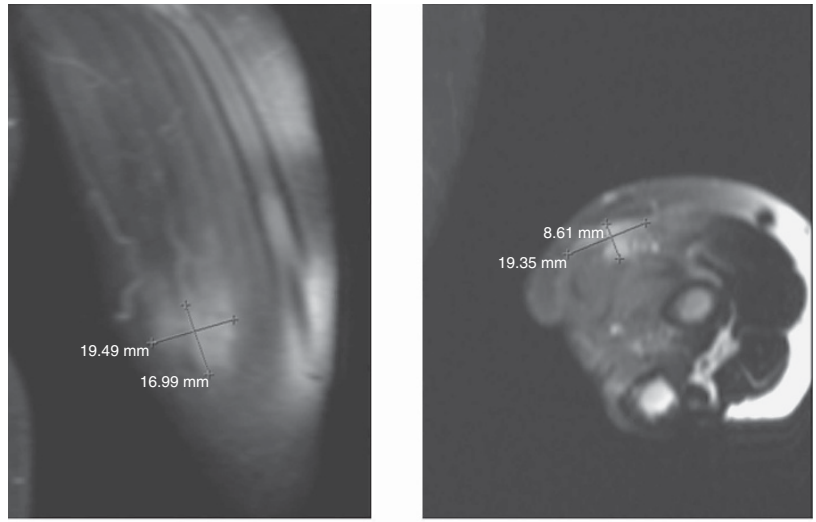

6 Weeks after TM-ILP
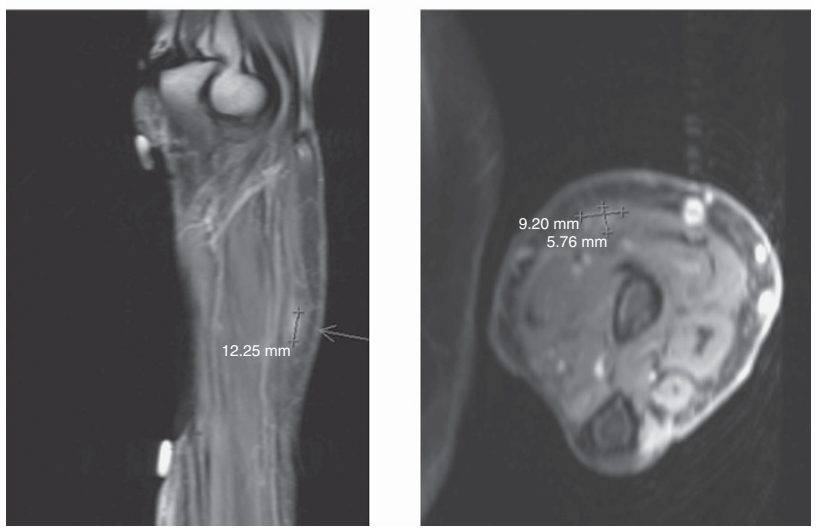

Figure 4. This superficial tumour of the forearm exhibited reductions in both size and contrast medium enhancement. MRI scan (T1, fat supressed with Gadolinium contrast medium enhancement) of an STS with a good response to TM-ILP before and 6 weeks after TM-ILP (patient no. 7).

reaction to treat tumours goes back to the late nineteenth century, when William Coley attempted to treat sarcoma by inducing a local bacterial infection (Wiemann and Starnes, 1994). Much later, it became obvious that TNF-alpha was one of the driving agents responsible for the inflammatory reaction and thus tumour destruction. This insight ultimately led to TNF-alpha being applied for isolated limb perfusion (Eggermont et al, 1996). The inflammatory cascade set in motion by TNF-alpha during TM-ILP can be observed early throughout the whole tumour (Eggermont et al, 1996), and there is an increase in systemic pro-inflammatory cytokines after TM-ILP (Hohenberger et al, 1997; Ferroni et al, 2001). The capillary leakage that results from TNFinduced inflammation is considered to be significantly higher in the tumour endothelium than in the endothelium of normal tissue, thus allowing the selective accumulation of the alkylating agent melphalan in tumour tissue compared with skin and muscle tissues (de Wilt et al, 2000; Hoving et al, 2006). Because of the high doses of TNF-alpha that are necessary to achieve effective tumour therapy using TM-ILP (a total dose of between 1 and $2 \mathrm{mg}$ is applied in the extremities), the treatment can only be performed under conditions of temporary vascular isolation of the limb from the systemic circulation. Otherwise, the severe side effects of TNFalpha would lead to systemic inflammatory response syndrome (Natanson et al, 1989; Schirmer et al, 1989), which carries a high risk of selective or even multiple organ failure (Eichacker et al, 1991).

In the present study, significant, pronounced tumour regression was achieved in almost all patients treated by TM-ILP, as indicated

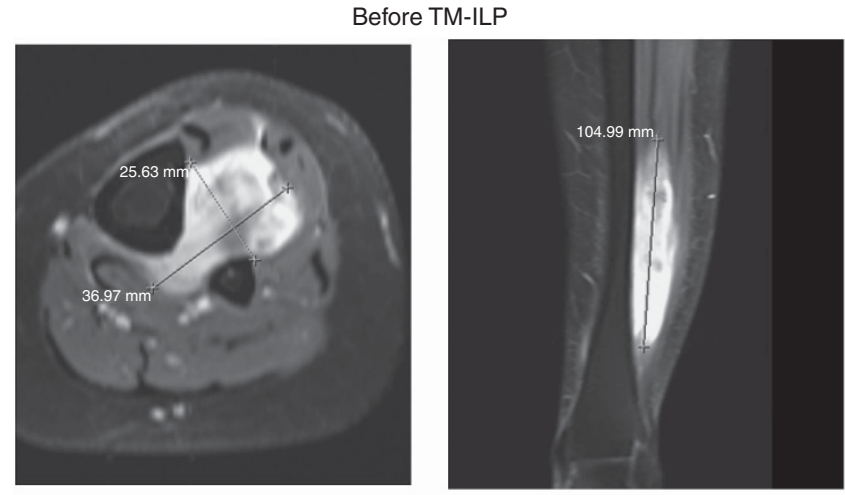

6 Weeks after TM-ILP
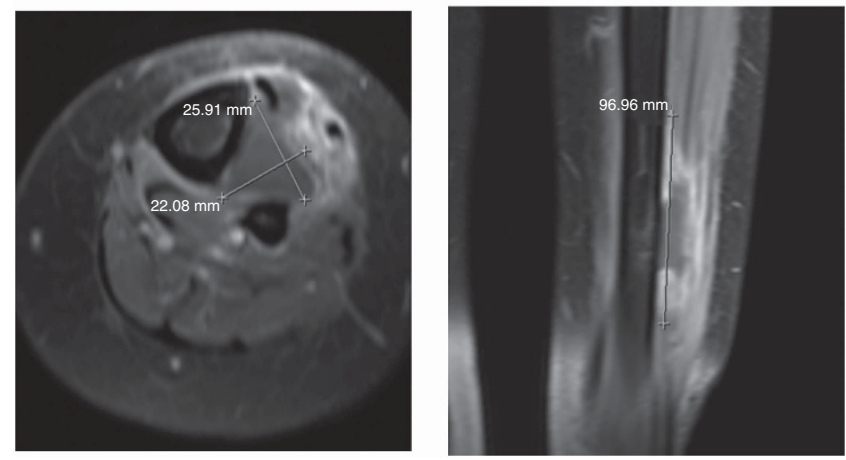

Figure 5. This superficial tumour of the lower leg exhibited a moderate decrease in size and a strong decrease in contrast medium enhancement. MRI scan (T1, fat supressed with Gadolinium contrast medium enhancement) of an STS with an excellent response to TM-ILP before and 6 weeks after TM-ILP (patient no. 1).

by histopathological examination of resection specimens and by MRI scans (Table 3). These results are similar to those reported by other studies (de Wilt et al, 2000; Hoving et al, 2006). In contrast, soft tissue sarcomas have been reported to not shrink significantly after pre-treatment with TM-ILP or chemotherapy (Stacchiotti et al, 2009; Grabellus et al, 2012b). In agreement with these findings, despite the positive response to TM-ILP, there was still a sufficiently significant residual tumour in all patients of the present study (between 20 and $100 \%$ of the original size) to allow measurement by $\mathrm{O} 2 \mathrm{C}$.

During and following TM-ILP, microvascular blood flow increased in both the tumour and normal muscle tissues (Figure 3 ). In contrast, $\mathrm{SO}_{2}$ remained constant or, at an early time point, even decreased, in accordance with the findings from Jakob et al (2012), who observed a considerable decrease in the tumour oxygen partial pressure towards the end of the TM-ILP procedure using needle oxygen probes. Both the increased microvascular blood flow and the increased oxygen consumption, as indicated by the constant or even decreased $\mathrm{SO}_{2}$, are in agreement with a longlasting inflammatory reaction in both tumour and muscle tissues (as also revealed by distinct inflammation of the whole extremity treated by TM-ILP). However, they do not provide any information about the success of the tumour treatment, especially regarding size reduction, or the remodelling processes within the tumour tissue. These results do indicate that primary impairment of microvascular perfusion was not the underlying reason for the success of tumour treatment by TM-ILP in our patients. This result is in marked contrast with one of the currently prevailing theories of tumour treatment by TM-ILP. According to this theory, overactivation of endothelial cells and leukocytes leads to rapid restriction of blood flow in the tumour vessels, which is the initial 
and decisive event in tumour destruction. This concept is based on experimental studies performed on animals (Nooijen et al, 1996; Hoving et $a l, 2006)$ and also is supported by clinical data, such as contrast-medium-enhanced Doppler sonography, for which there was a significant decrease in tumour blood flow already 1-day postTM-ILP (Lassau et al, 2005). The reason for the apparent discrepancy between the results obtained for our patients by the microvascular measurements with the $\mathrm{O} 2 \mathrm{C}$ and the data reported above is unknown at present. The discrepancy may partly be explained by the fact that our measurements were performed only within a distinct volume of the tumour tissue, that is, between 1 and $17 \mathrm{~mm}$ from the skin surface, which may give preference to values that result from the inflammatory margin of the tumour, an area with especially high blood flow (van Rijswijk et al, 2003). Alternatively, at the microscopic level, impairment of perfusion of one microvessel may be overcompensated by increased perfusion of another neighbouring microvessel, thereby resulting in increased perfusion of the respective area.

Several weeks after TM-ILP, the microvascular blood flow in the tumour tissue decreased to levels lower than before TM-ILP but comparable to normal muscle tissue (Figure $3 \mathrm{~B}$ ). Thus, the $\mathrm{O} 2 \mathrm{C}$ measurements indicate a decrease in vascularisation of the residual tumour as well, in agreement with, but not as distinct as, the results of MRI scans and angiography performed several weeks after TMILP (Olieman et al, 1997; van Rijswijk et al, 2003; Vanel et al, 2004).

In conclusion, this study casts doubt on the assumption that early vascular destruction is the key mechanism responsible for tumour necrosis after TM-ILP. Instead, the data suggest that the inflammation induced by TM-ILP is stronger and longer lasting than initially believed and is, in addition to the direct cytotoxic effects of melphalan, predominantly responsible for the successful application of TM-ILP for tumour treatment. Because of the low number of patients enrolled in this study, further research is required to substantiate this conclusion.

\section{CONFLICT OF INTEREST}

The authors declare no conflict of interest.

\section{REFERENCES}

Beckert S, Witte MB, Konigsrainer A, Coerper S (2004) The impact of the Micro-Lightguide $\mathrm{O} 2 \mathrm{C}$ for the quantification of tissue ischemia in diabetic foot ulcers. Diabetes Care 27(12): 2863-2867.

Bonvalot S, Rimareix F, Causeret S, Le Pechoux C, Boulet B, Terrier P, Le Cesne A, Muret J (2009) Hyperthermic isolated limb perfusion in locally advanced soft tissue sarcoma and progressive desmoid-type fibromatosis with TNF $1 \mathrm{mg}$ and melphalan (T1-M HILP) is safe and efficient. Ann Surg Oncol 16(12): 3350-3357.

de Wilt JH, ten Hagen TL, de Boeck G, van Tiel ST, de Bruijn EA, Eggermont AM (2000) Tumour necrosis factor alpha increases melphalan concentration in tumour tissue after isolated limb perfusion. Br J Cancer 82(5): $1000-1003$

Derfuss T (2012) O2C (oxygen to see): A short overview of the working method. Giessen: LEA Medizintechnik GmbH http://www.lea.de/eng/ indexe.html.

Deroose JP, Eggermont AM, van Geel AN, Burger JW, den Bakker MA, de Wilt JH, Verhoef C (2011a) Long-term results of tumor necrosis factor alpha- and melphalan-based isolated limb perfusion in locally advanced extremity soft tissue sarcomas. J Clin Oncol 29(30): 4036-4044.

Deroose JP, Eggermont AM, van Geel AN, de Wilt JH, Burger JW, Verhoef C (2012) 20 years experience of TNF-based isolated limb perfusion for intransit melanoma metastases: TNF dose matters. Ann Surg Oncol 19(2): 627-635.

Deroose JP, Grunhagen DJ, van Geel AN, de Wilt JH, Eggermont AM, Verhoef C (2011b) Long-term outcome of isolated limb perfusion with tumour necrosis factor-alpha for patients with melanoma in-transit metastases. Br J Surg 98(11): 1573-1580.

Eggermont AM, Schraffordt Koops H, Klausner JM, Kroon BB, Schlag PM, Lienard D, van Geel AN, Hoekstra HJ, Meller I, Nieweg OE, Kettelhack C, Ben-Ari G, Pector JC, Lejeune FJ (1996) Isolated limb perfusion with tumor necrosis factor and melphalan for limb salvage in 186 patients with locally advanced soft tissue extremity sarcomas. The cumulative multicenter European experience. Ann Surg 224(6): 756-764.

Eichacker PQ, Hoffman WD, Farese A, Banks SM, Kuo GC, MacVittie TJ, Natanson C (1991) TNF but not IL-1 in dogs causes lethal lung injury and multiple organ dysfunction similar to human sepsis. J Appl Physiol 71(5): 1979-1989.

Ferroni P, Di Filippo F, Martini F, Spila A, D’Alessandro T, Cavaliere F, Anza M, Garinei R, Aloe S, Carone MD, Gazzaniga PP, Guadagni F (2001) Effects of isolated limb perfusion with tumor necrosis factor-alpha on circulating levels of proinflammatory cytokines. J Immunother 24(4): 354-362.

Fletcher CDM. World Health OrganizationInternational Agency for Research on Cancer (2013) In WHO Classification of Tumours of Soft Tissue and Bone. 4th edn, Vol. 5IARC Press: Lyon.

Grabellus F, Kraft C, Sheu-Grabellus SY, Bauer S, Podleska LE, Lauenstein TC, Pottgen C, Konik MJ, Schmid KW, Taeger G (2011) Tumor vascularization and histopathologic regression of soft tissue sarcomas treated with isolated limb perfusion with TNF-alpha and melphalan. J Surg Oncol 103(5): 371-379.

Grabellus F, Podleska LE, Sheu SY, Bauer S, Pottgen C, Kloeters C, Hoiczyk M, Lauenstein TC, Schmid KW, Taeger G (2012a) Neoadjuvant treatment improves capsular integrity and the width of the fibrous capsule of highgrade soft-tissue sarcomas. Eur J Surg Oncol 39(1): 61-67.

Grabellus F, Stylianou E, Umutlu L, Sheu SY, Lehmann N, Taeger G, Lauenstein TC (2012b) Size-based clinical response evaluation is insufficient to assess clinical response of sarcomas treated with isolated limb perfusion with TNF-alpha and melphalan. Ann Surg Oncol 19(11): $3375-3385$.

Grunhagen DJ, de Wilt JH, Graveland WJ, Verhoef C, van Geel AN, Eggermont AM (2006) Outcome and prognostic factor analysis of 217 consecutive isolated limb perfusions with tumor necrosis factor-alpha and melphalan for limb-threatening soft tissue sarcoma. Cancer 106(8): 1776-1784.

Hendriksen EM, Span PN, Schuuring J, Peters JP, Sweep FC, van der Kogel AJ, Bussink J (2009) Angiogenesis, hypoxia and VEGF expression during tumour growth in a human xenograft tumour model. Microvasc Res 77(2): 96-103.

Hohenberger P, Haier J, Kettelhack C, Schulze G, Schlag PM (1997) [Assessment of regional and systemic toxicity of isolated hyperthermic extremity perfusion with tumor necrosis factor-alpha and melphalan]. Chirurg 68(9): 914-920.

Hoving S, Seynhaeve AL, van Tiel ST, aan de Wiel-Ambagtsheer G, de Bruijn EA, Eggermont AM, ten Hagen TL (2006) Early destruction of tumor vasculature in tumor necrosis factor-alpha-based isolated limb perfusion is responsible for tumor response. Anticancer Drugs 17(8): 949-959.

Jakob J, von Rege I, Weiss C, Hohenberger P (2012) Impact of hyperthermic isolated limb perfusion on tumour oxygenation in soft tissue sarcoma. Int $J$ Hyperthermia 28(7): 591-596.

Jorgensen LP, Schroeder TV (2012) Micro-lightguide spectrophotometry for tissue perfusion in ischemic limbs. J Vasc Surg 56(3): 746-752.

Lassau N, Lamuraglia M, Vanel D, Le Cesne A, Chami L, Jaziri S, Terrier P, Roche A, Leclere J, Bonvalot S (2005) Doppler US with perfusion software and contrast medium injection in the early evaluation of isolated limb perfusion of limb sarcomas: prospective study of 49 cases. Ann Oncol 16(7): 1054-1060.

Natanson C, Eichenholz PW, Danner RL, Eichacker PQ, Hoffman WD, Kuo GC, Banks SM, MacVittie TJ, Parrillo JE (1989) Endotoxin and tumor necrosis factor challenges in dogs simulate the cardiovascular profile of human septic shock. J Exp Med 169(3): 823-832.

Nooijen PT, Manusama ER, Eggermont AM, Schalkwijk L, Stavast J, Marquet RL, de Waal RM, Ruiter DJ (1996) Synergistic effects of TNF-alpha and melphalan in an isolated limb perfusion model of rat sarcoma: a histopathological, immunohistochemical and electron microscopical study. Br J Cancer 74(12): 1908-1915.

Nordsmark M, Alsner J, Keller J, Nielsen OS, Jensen OM, Horsman MR, Overgaard J (2001) Hypoxia in human soft tissue sarcomas: adverse impact on survival and no association with p53 mutations. Br J Cancer 84(8): 1070-1075.

Olieman AF, van Ginkel RJ, Hoekstra HJ, Mooyaart EL, Molenaar WM, Koops HS (1997) Angiographic response of locally advanced soft-tissue 
sarcoma following hyperthermic isolated limb perfusion with tumor necrosis factor. Ann Surg Oncol 4(1): 64-69.

Posner MC, Lienard D, Lejeune FJ, Rosenfelder D, Kirkwood J (1995) Hyperthermic isolated limb perfusion with tumor necrosis factor alone for melanoma. Cancer J Sci Am 1(4): 274-280.

Rofstad EK, Danielsen T (1998) Hypoxia-induced angiogenesis and vascular endothelial growth factor secretion in human melanoma. $\mathrm{Br} J$ Cancer 77(6): 897-902.

Salzer-Kuntschik M, Delling G, Beron G, Sigmund R (1983) Morphological grades of regression in osteosarcoma after polychemotherapy - study COSS 80. J Cancer Res Clin Oncol 106 Suppl: 21-24.

Schirmer WJ, Schirmer JM, Fry DE (1989) Recombinant human tumor necrosis factor produces hemodynamic changes characteristic of sepsis and endotoxemia. Arch Surg 124(4): 445-448.

Stacchiotti S, Collini P, Messina A, Morosi C, Barisella M, Bertulli R, Piovesan C, Dileo P, Torri V, Gronchi A, Casali PG (2009) High-grade soft-tissue sarcomas: tumor response assessment-pilot study to assess the correlation between radiologic and pathologic response by using RECIST and Choi criteria. Radiology 251(2): 447-456.

Taeger G, Grabellus F, Podleska LE, Muller S, Ruchholtz S (2008) Effectiveness of regional chemotherapy with TNF-alpha/melphalan in advanced soft tissue sarcoma of the extremities. Int J Hyperthermia 24(3): 193-203. van Rijswijk CS, Geirnaerdt MJ, Hogendoorn PC, Peterse JL, van Coevorden F, Taminiau AH, Tollenaar RA, Kroon BB, Bloem JL (2003) Dynamic contrast-enhanced MR imaging in monitoring response to isolated limb perfusion in high-grade soft tissue sarcoma: initial results. Eur Radiol 13(8): 1849-1858.

Vanel D, Bonvalot S, Guinebretiere JM, Petrow P, Dromain C, Caillet H (2004) MR imaging in the evaluation of isolated limb perfusion: a prospective study of 18 cases. Skeletal Radiol 33(3): 150-156.

Vaupel P, Schlenger K, Knoop C, Hockel M (1991) Oxygenation of human tumors: evaluation of tissue oxygen distribution in breast cancers by computerized $\mathrm{O} 2$ tension measurements. Cancer Res 51(12): 3316-3322.

Wiemann B, Starnes CO (1994) Coley's toxins, tumor necrosis factor and cancer research: a historical perspective. Pharmacol Ther 64(3): $529-564$.

This work is published under the standard license to publish agreement. After 12 months the work will become freely available and the license terms will switch to a Creative Commons AttributionNonCommercial-Share Alike 4.0 Unported License 